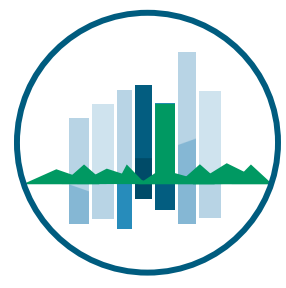

True Smart and Green City?

8th Conference of the

International Forum on Urbanism
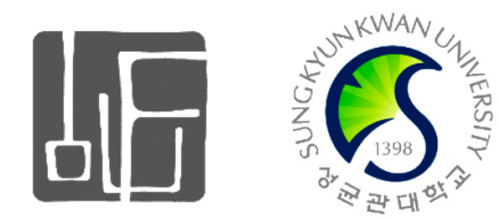

Conference Proceedings Paper

\title{
Campus WU A Holistic History
}

\section{Laura P. Spinadel}

BUSarchitektur \& BOA büro für offensive aleatorik, Schlugasse 36/2/1, 1180 Vienna, Austria; E-Mail: spinadel@busarchitektur.com; Tel.: +43 140387 57; Fax: +43 1403875714

\begin{abstract}
To create architecture today is a gnomic game. The rules of the game are paradoxical, players are continually changing their minds and every operational process ends up being self-referential (1). The basic democratic rights pertaining to the built environment are: the right to natural light, the right to visual perception and the right to water. Therefore, the job of an architect nowadays is to find a new balance between ecology and urban planning. Our aim as thinkers and operators should be to once again play an active role in environmental quality optimization by acknowledging the complexity of this process and searching for sustainable changes. BUSarchitektur has been working on issues affecting our contemporary society since it was founded in 1986. BOA office for advanced randomness has been developing cultural interactions since its establishment in 2003. Through their proposals both companies develop realistic utopias that help us to value and redefine our inherited legacy in a conscientious and committed way. The new Campus WU project was launched in 2005 within the academic setting of the Vienna University of Economics and Business. The project culminated in 2013 with the handing over of the finished university complex within its budgetary framework of EUR 500 million. It is the largest University of Economics in the European Union with a population of 25,000 students, teachers and administrative staff and is moving into a neighborhood with approximately 100,000 inhabitants. This is where future generations of, hopefully competent, economists will be trained. It is a strategic example of a star system, employed by the user, which seeks to obtain the necessary funding by awarding the projects to Zaha Hadid Architects, Hamburg - CRABstudio, London - Carme Pinós, Barcelona - NO.mad Madrid, Hitoshi Abe - Sendai as well as to the Masterplan winner, Vienna's BUSarchitektur. The democratic organization of users, the power structures of the state, leading agencies' inspections, monitoring costs and budgets, branding inflicted on architecture, multiple regulations, contract award mechanisms, the historical burden of a privileged place, the social tensions associated with one of the established centers of prostitution, the dissatisfaction of the student population, etc. - these are some of the factors
\end{abstract}


causing stakeholder interests to be in permanent unstable equilibrium. As a result, the Masterplan authors' constant search for a holistic equilibrium continued throughout the entire project process and into the execution, with an unstable balance of power between users, residents, developers, politicians, experts and author design implementers. We will present the architect's roles in three micro-worlds, which seek to put forward the idea that a sustainable balance between the four quadrants (2) is not a pre-existing element of our work as architects and urban planners. Ultimately, striking the balance between personal achievement, objectifiable technology, cultural interaction and social urges, means recognizing the importance of permanently changing our point of view and encourages us to take other factors into consideration. Every single detail should force us to recognize the many different ways a given intervention's micro-action can be interpreted and to proceed accordingly. However, our open-minded approach to searching for added-value, which must necessarily incorporate our actions, often leads us to adopt casual strategies for managing projects. The imbalance between the four quadrants is the starting state that compels us to set off interrelated chain reactions in an attempt to awaken the potential for coOpetition (3). This potential is present both in the direct actors and in the domino effect that will occur once we take control of the reality in which we act. CoOpeting public and private actors that acknowledge the simultaneous presence of both cooperation and competition when talking about quality of life and capital repayment. Competing cooperatively in order to successfully invent and develop alternative design mechanisms to those of globalization. Intellectual curiosity as a journey to discover not-so-obvious game theory applications in architecture this is our way to play an active role in our daily productive output. The game played is a game of society since it leads to the socialization of the individual in a virtual community and, as a consequence, to the development of a real community. The only way for Campus to have a future is if we activate the urban potential of the educational habitat.

Keywords: Architecture, Urbanism, Project Development, Integral Design and Building, Master Planning, Executive Planning, Landscape, Location Marketing, Urban Communication Strategies and Interactions, Multimedia, Visualization, Realistic Utopias

\section{Operational randomness in an interactive urbanism}

To create architecture today is a gnomic game. The rules of the game are paradoxical, players are continually changing their minds and every operational process ends up being self-referential (1). The basic democratic rights pertaining to the built environment are: the right to natural light, the right to visual perception and the right to water. Therefore, the job of an architect nowadays is to find a new balance between ecology and urban planning. Our aim as thinkers and operators should be to once again play an active role in environmental quality optimization by acknowledging the complexity of this process and searching for sustainable changes. 


\section{Campus WU A holistic history}

BUSarchitektur has been working on issues affecting our contemporary society since it was founded in 1986. BOA office for advanced randomness has been developing cultural interactions since its establishment in 2003. Through their proposals both companies develop realistic utopias that help us to value and redefine our inherited legacy in a conscientious and committed way.

The new Campus WU project was launched in 2005 within the academic setting of the Vienna University of Economics and Business. The project culminated in 2013 with the handing over of the finished university complex within its budgetary framework of EUR 500 million. It is the largest University of Economics in the European Union with a population of 25,000 students, teachers and administrative staff and is moving into a neighborhood with approximately 100,000 inhabitants. This is where future generations of, hopefully competent, economists will be trained. It is a strategic example of a star system, employed by the user, which seeks to obtain the necessary funding by awarding the projects to Zaha Hadid Architects, Hamburg - CRABstudio, London - Carme Pinós, Barcelona - NO.mad Madrid - Hitoshi Abe, Sendai as well as to the Masterplan winner, Vienna's BUSarchitektur.

The democratic organization of users, the power structures of the state, leading agencies' inspections, monitoring costs and budgets, branding inflicted on architecture, multiple regulations, contract award mechanisms, the historical burden of a privileged place, the social tensions associated with one of the established centers of prostitution, the dissatisfaction of the student population, etc. - these are some of the factors causing stakeholder interests to be in permanent unstable equilibrium.

As a result, the Masterplan authors' constant search for a holistic equilibrium continued throughout the entire project process and into the execution, with an unstable balance of power between users, residents, developers, politicians, experts and author design implementers. We will present the architect's roles in three micro-worlds, which seek to put forward the idea that a sustainable balance between the four quadrants (2) is not a pre-existing element of our work as architects and urban planners.

\section{Process Diagram}

Masterplanning Campus WU for the development and realization of the University.

Figure 1. Seven roles on Campus WU: Comprehensive Master Planner, General Planner, Teaching Center Architect, Open Space Designer, Parking Planner, Documentalists and Communicators.

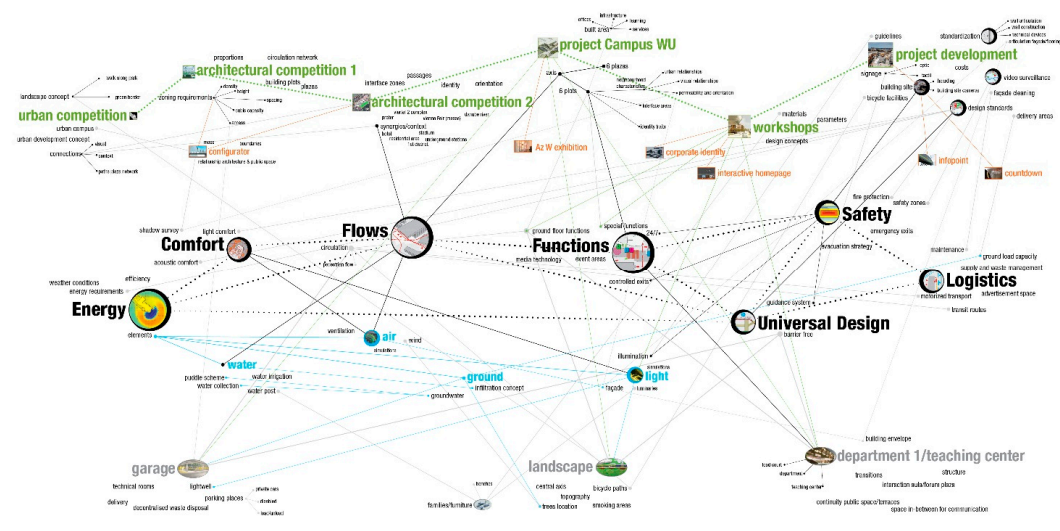


Is architecture shaping society?

The Masterplan for the Vienna University (WU) Campus by BUSarchitektur is by nature as complex as it is evolutionary. It embodies a multivalent negotiation of scales, conceptual principles, architectural territories and operative methodologies. Its success as a highly accomplished work of architecture and urbanism is attributable not only to the intricacies of this multifaceted negotiation, the comprehensiveness of its approach, and the high standards to which the architecture aspires, but also to the inventiveness with which the Master Plan, as a predefined product of urban and architectural history, was conceptually retooled in order to challenge its traditional deficiencies and ensure its alignment with the conceptual strategies embedded in BUS's design approach to the project. The Masterplan operates as both a largescale architecturally designed "schema" for the whole campus while also advancing multiple strategies to catalyze and control its generative processes and evolutionary development. In this sense, the Masterplan operates as an interactive device and abstract machine, a living body that is, in the end, a subject of its own material evolution. (4)

Figure 2. Urban interaction: Campus space flowing into the Teaching Center's Aula.

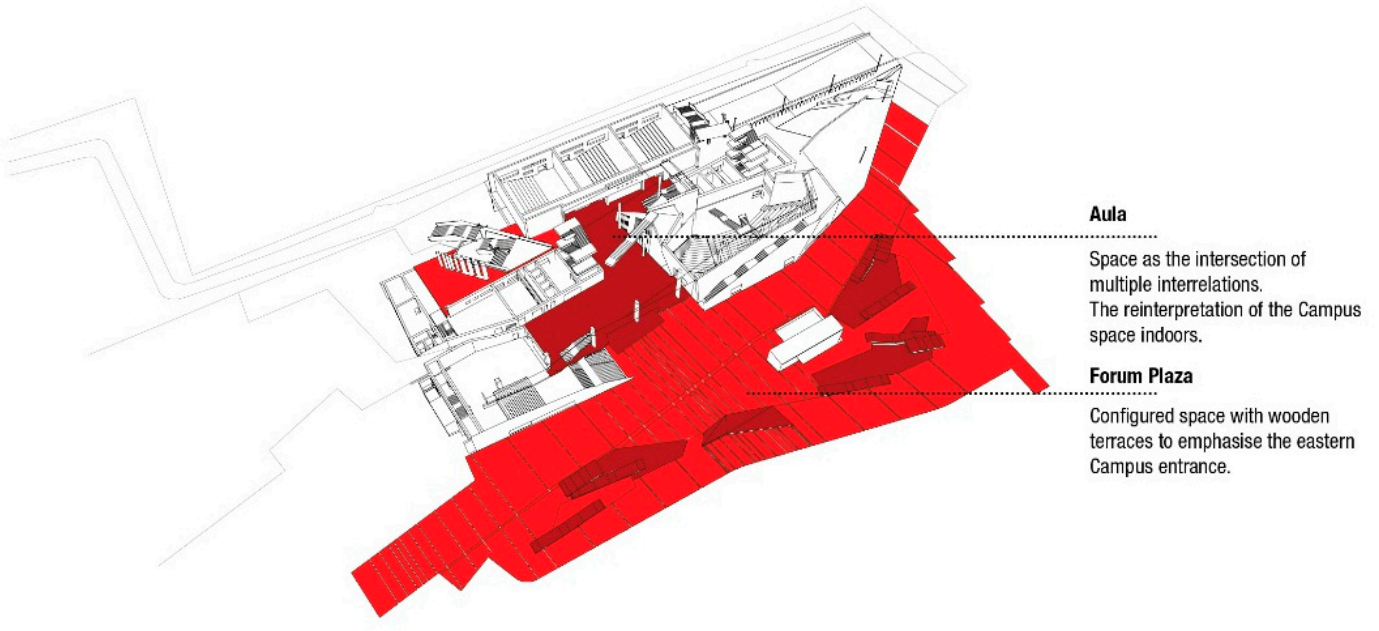

Can landscape qualify the environment?

The campus is a sequence of spaces which intertwine with each other. Each route forks in such a manner that the destinations can be reached via many different paths. Various stations for stopover and for activities are defined along these routes of the Walk Along Park. Each site seeks to encourage the exchange and the search for new paths towards learning. 
Figure 3. The Squares and multiple paths: Routes and stations always diverge.

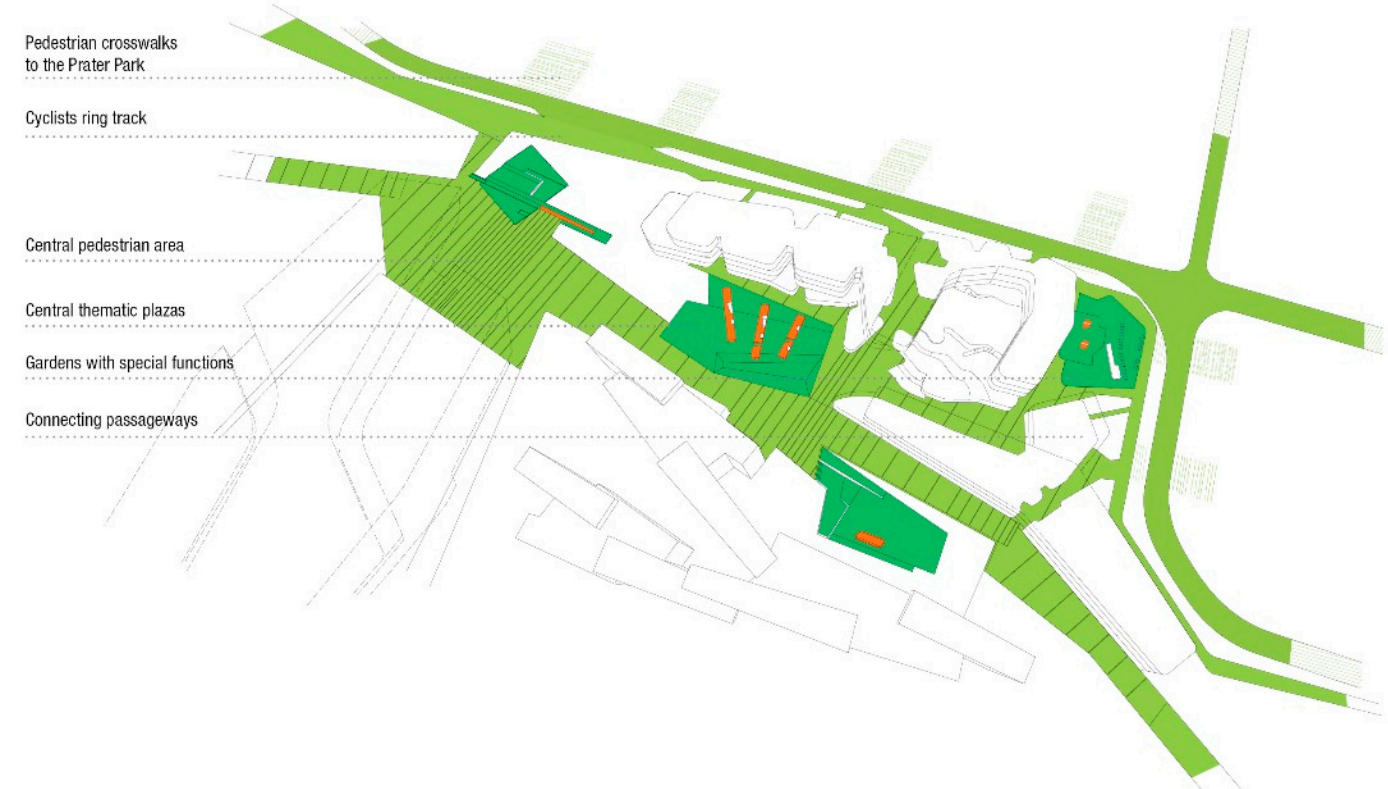

Should the architect submit to the market?

The structure on Plot 01 (Teaching Center), with a capacity of up to 4,585 users, is strongly characterized by a "pierced by paths" concept of open space. This design concept was applied both indoors and outdoors. The idea behind this approach is that individuals may discover and interpret the building along different leisure walks.

Figure 4. Emergency exits and evacuation routes in the Teaching Center: Basis for the evacuation simulation

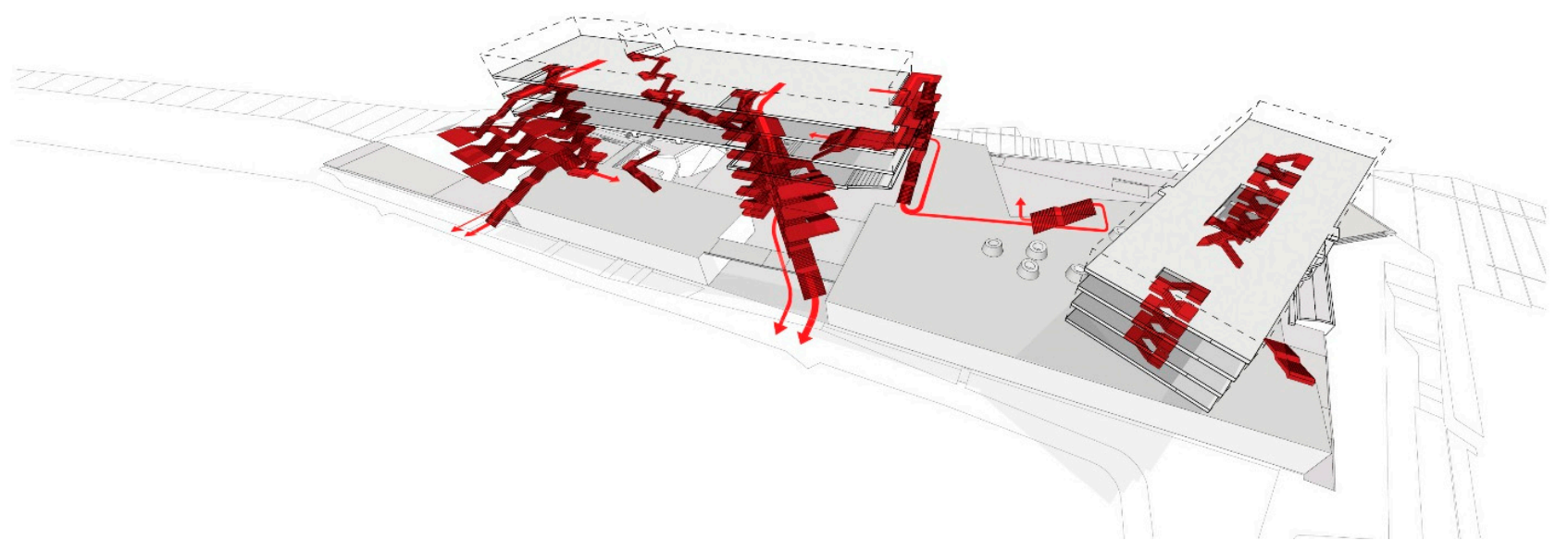

\section{Thematic modules for integral planning}

The Masterplan outlines the principles and major structural divisions, such as the designation of construction sites, building locations and open spaces. It is the basis of the architectural project and provides recommendations for individual buildings' designs. An integral Masterplan is the goal of the entire process. Designs, cooperative planning methods and visionary models are not only developed to 
meet building and development regulations but to embark on an overall coherent planning and execution process guided by the Campus WU Master Plan - a plan that hopes to fulfill criteria for emotional identification while also taking into account the complex logic of its creation. By way of a moderation process with the parties involved, the team of master planners combine building aspects with social, economic and contextual goals and requirements. It is the master planners' task to stop negative trends and to initiate positive impulses and visions, to improve the quality of life and work, to create long-term planning assurances, to foster cooperation and social networks, and to allow room to manoeuvre.

Figure 5. Light \& Safety: Potentialities for Freedom in the Educational Field.

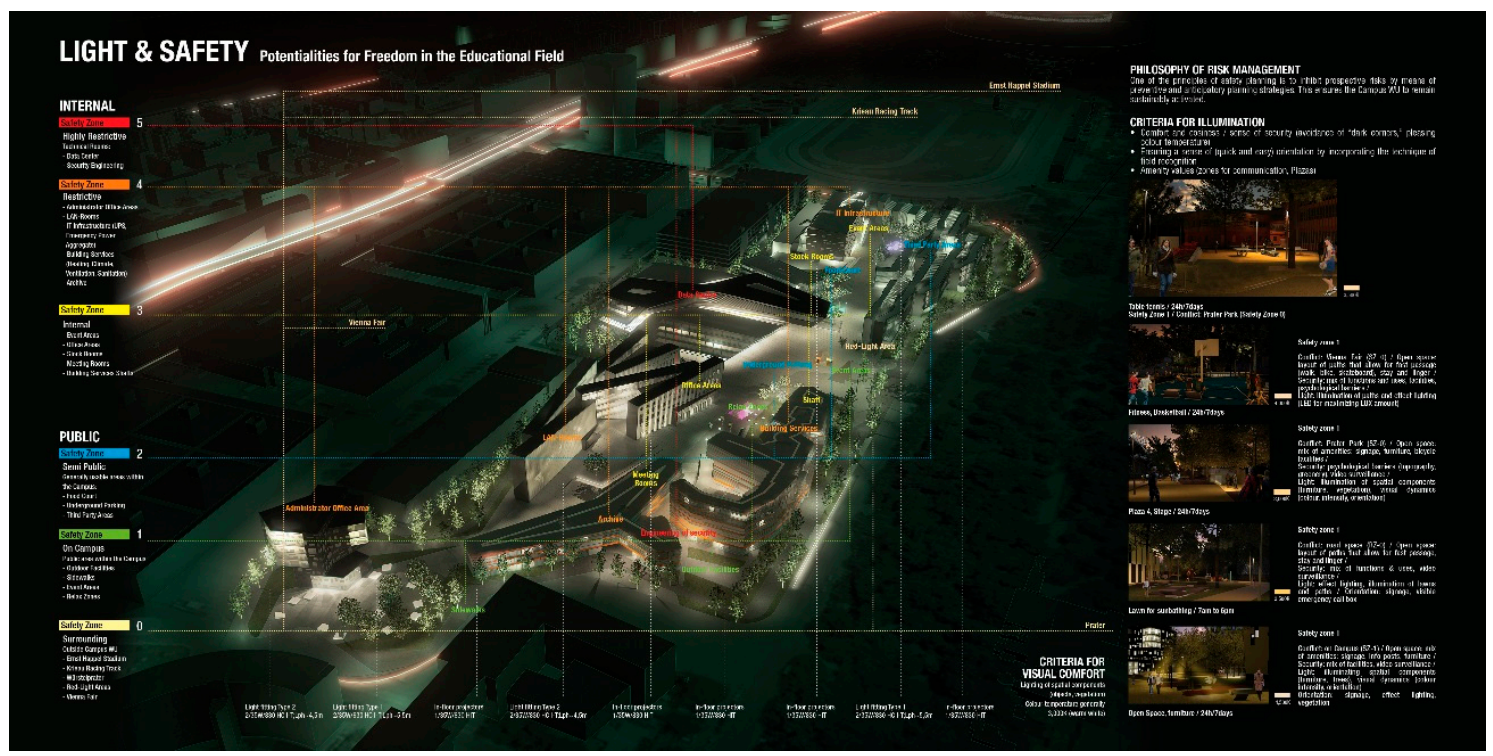

Figure 6. Energy \& Life Cycle: Self-sustainability within the Existing Ecosystem.
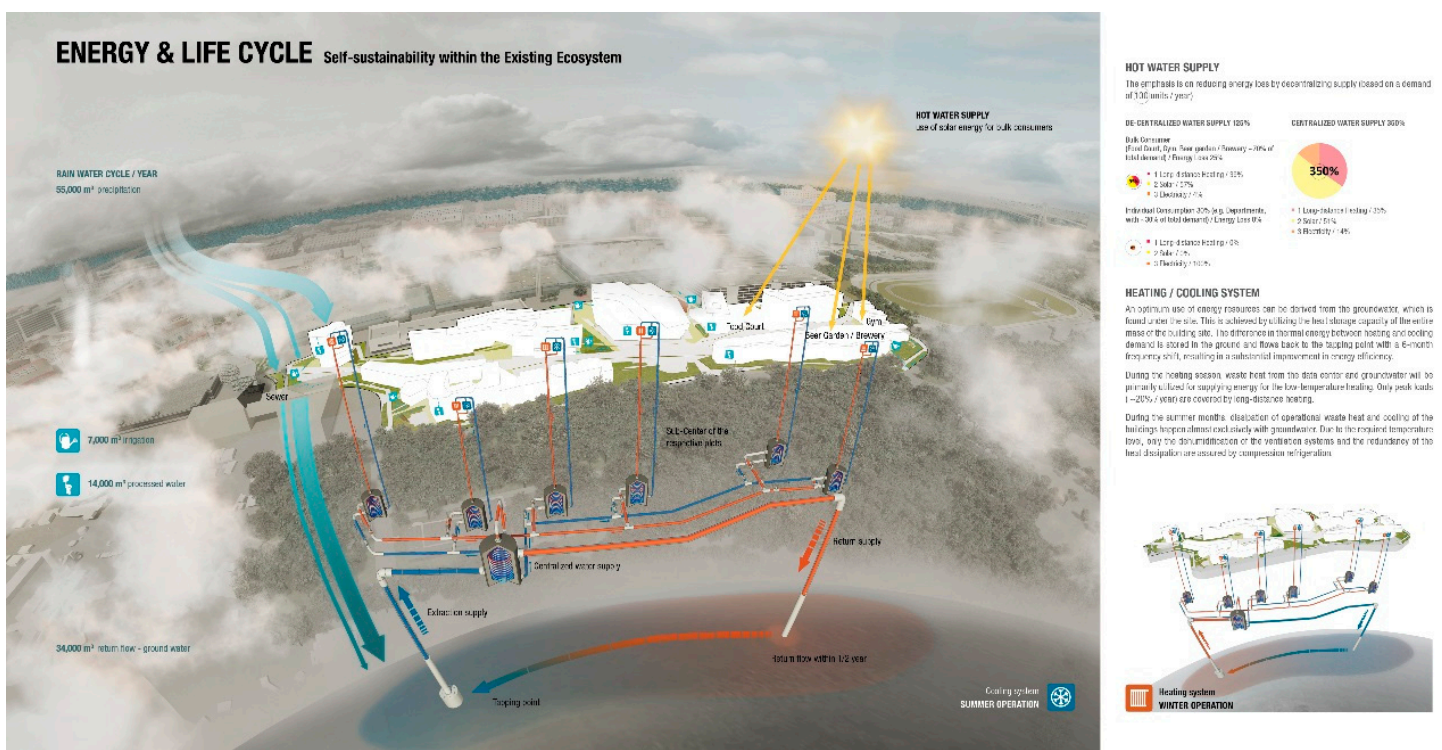
Figure 7. Spaces for Appropriation: At All times of the Year.

SPACES FOR APPROPRIATION At All times of the Year
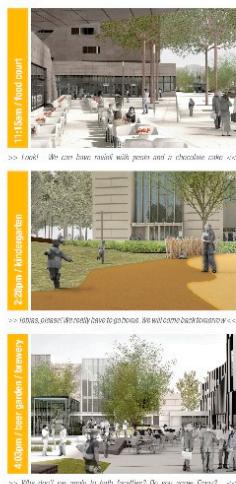

SPAIN

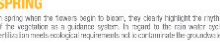
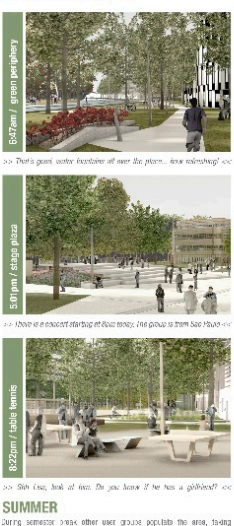

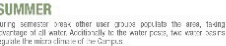
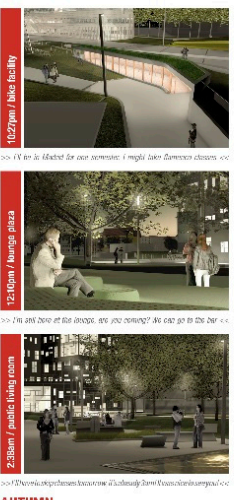

AUTUMN

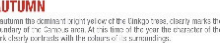
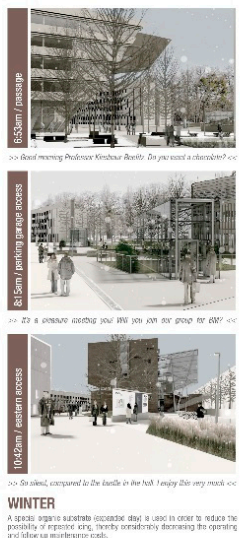

Figure 8. Integral Masterplan: Open Space as Interlinking Protagonist.

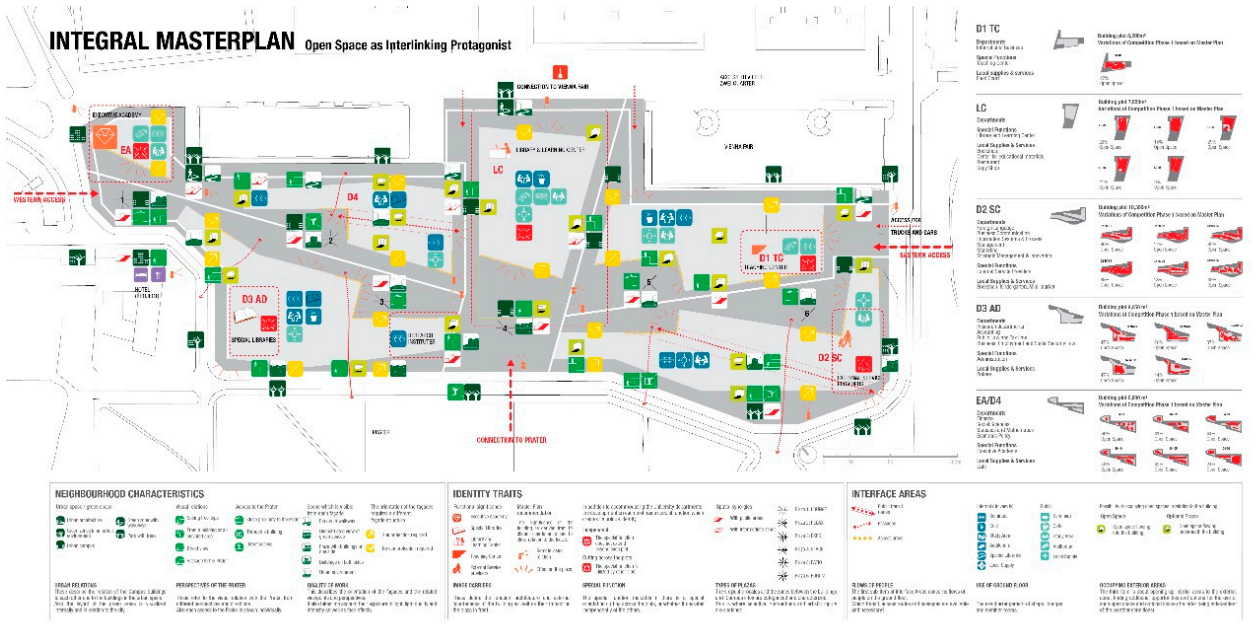

Figure 9. Configurators: Novel Tools for Negotiating \& Evaluating Spatial Qualities.

CONFIGURATORS Novel Tools for Negotiating \& Evaluating Spatial Qualities

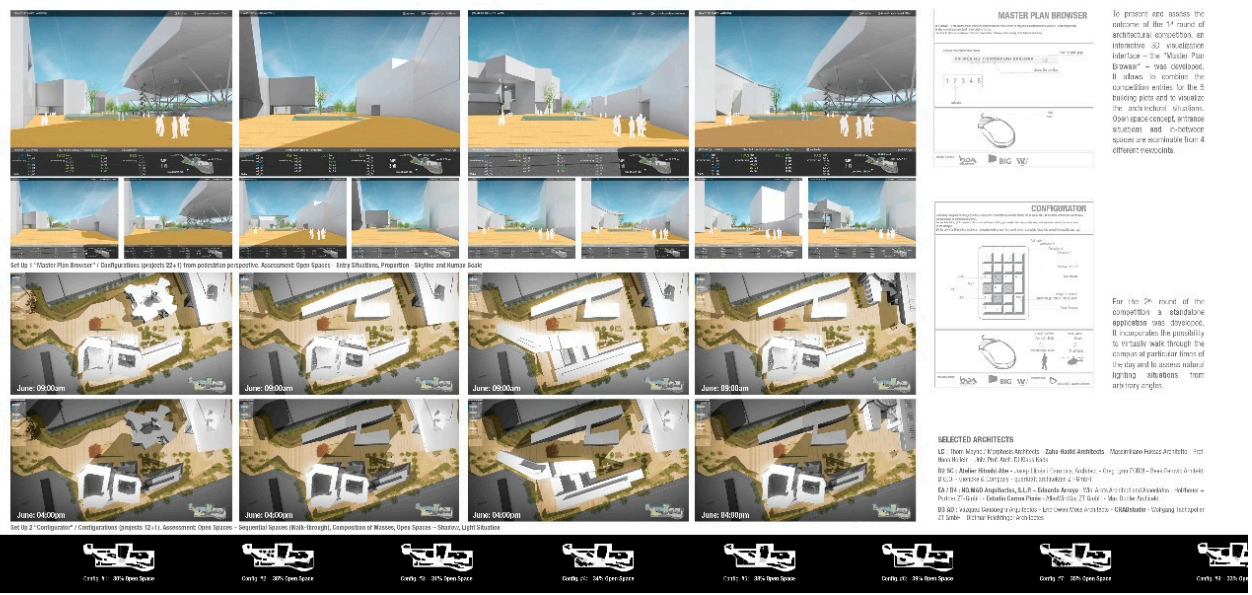


Figure 10. Walk along Park: Sampling Educational Life to Emphasize Collaborative Knowledge.

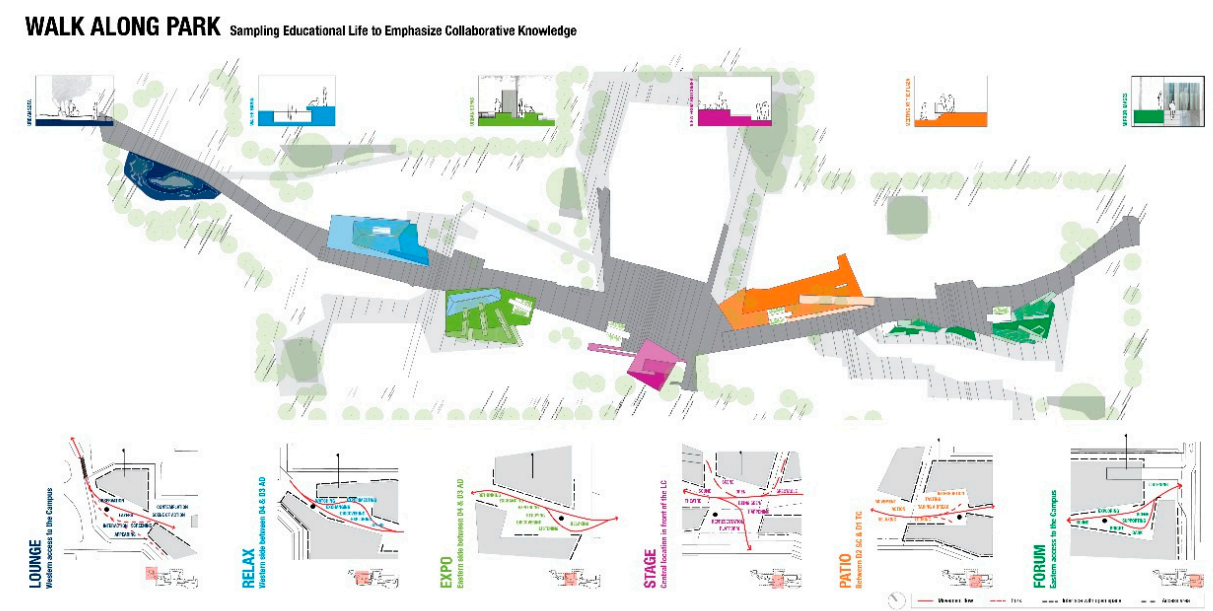

Figure 11. Contextual Synergies: Regional Significance and Community Building.

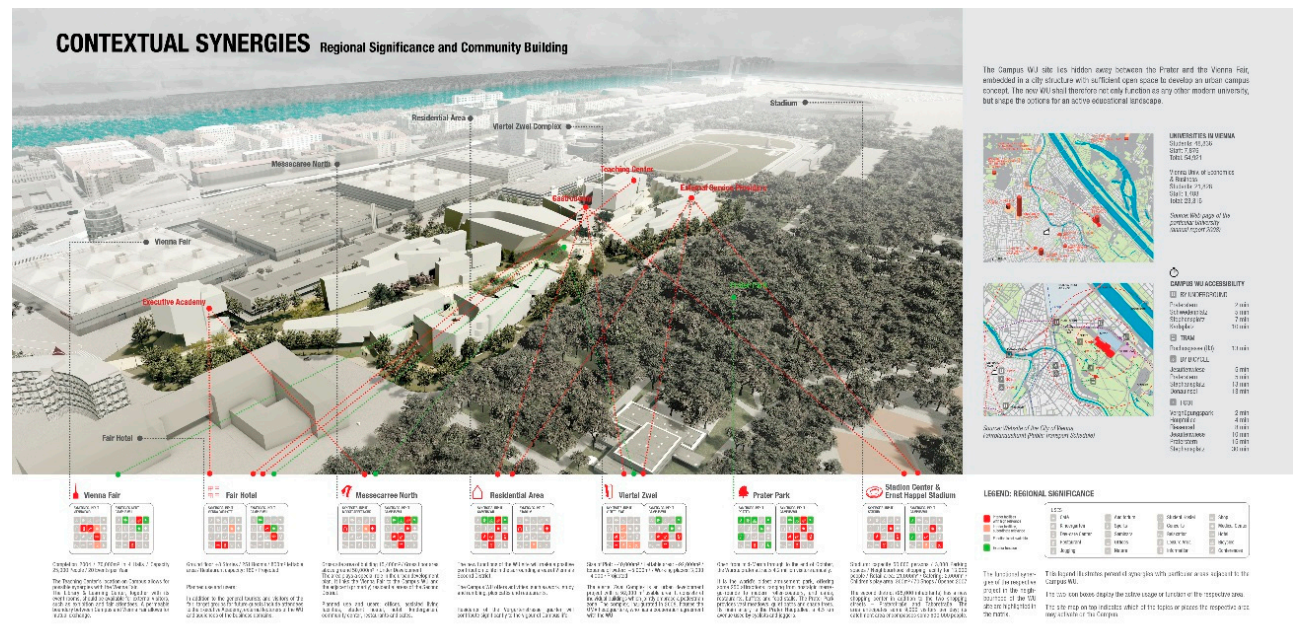

Figure 12. Open Spaces: Green Oasis - Pavillions in the University Garden.
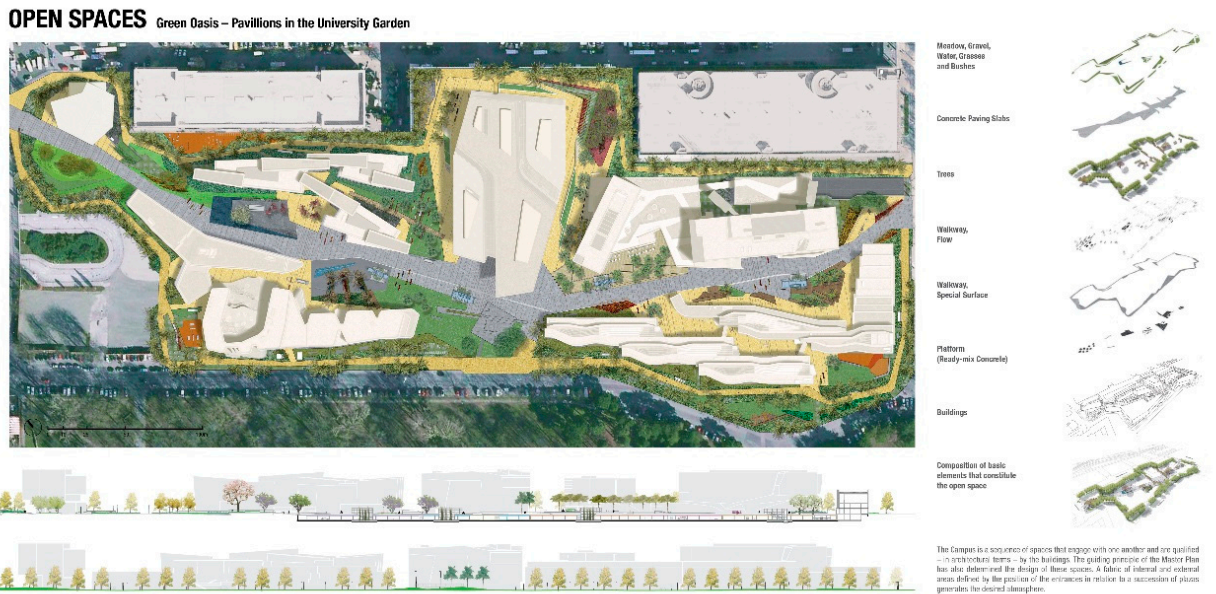
Figure 13. Gameboard of Realization: Multiplicity of Stakeholders Activating the Space

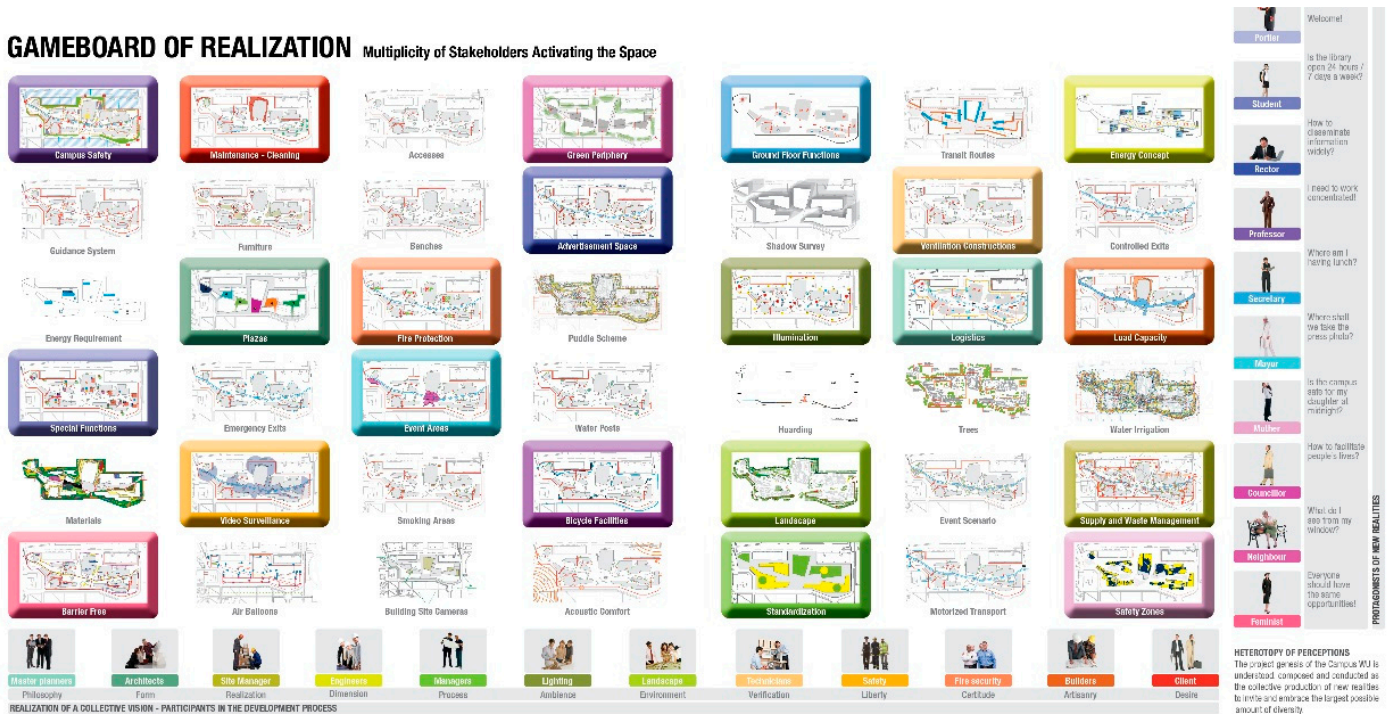

Figure 14. Ecological Urbanism: Intensities \& Densities: Encouraging Interaction in Public Spaces

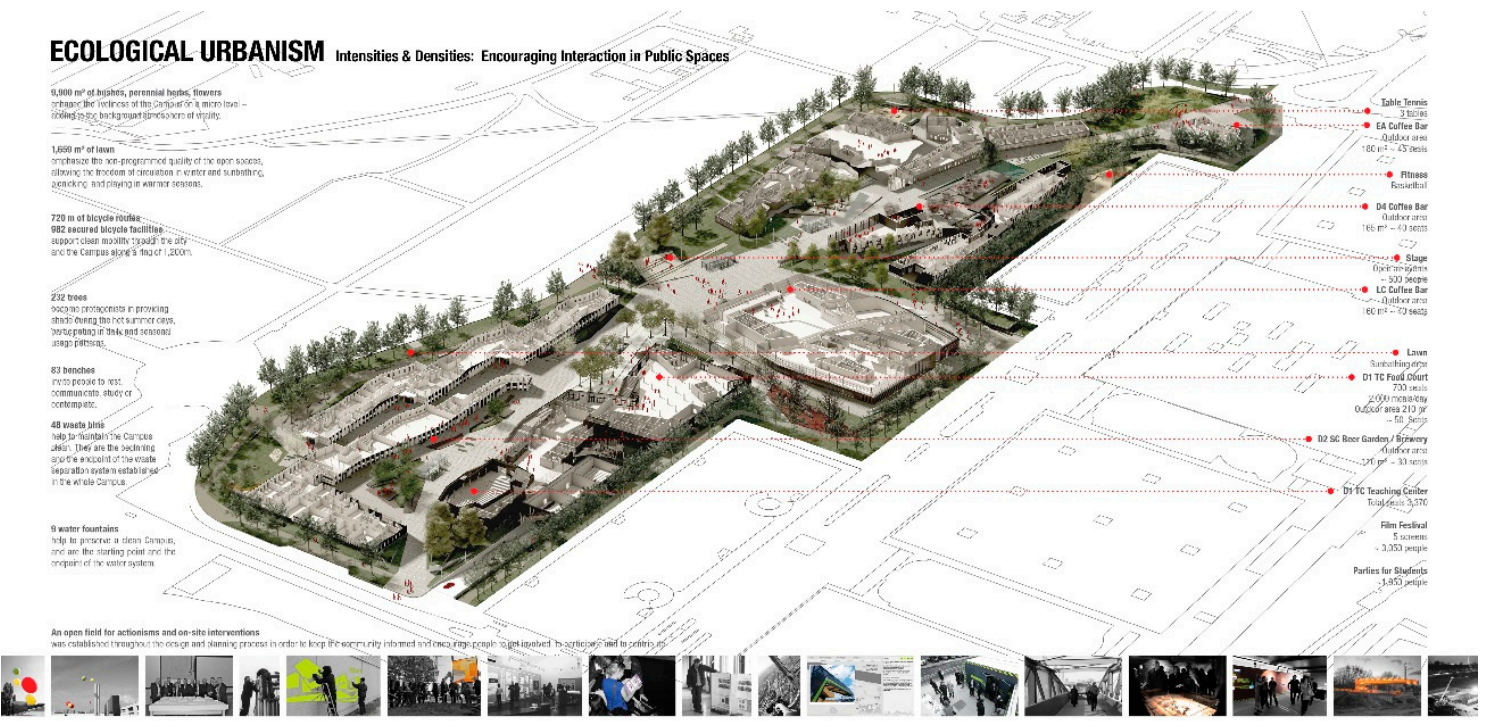

- energy efficiency of the new Campus WU in Vienna • form follows energy? • between efficiency and effectiveness • quality of life and individual comfort in the $24 / 7$ rhythm $\bullet \bullet$ recommendations for an intelligent architecture $\bullet$ renewable energies as a basis for a new values system $\bullet$ passive or active? $\bullet$ living with nature $\bullet \bullet$ emergence of a micro climate for the new campus $\mathrm{WU} \cdot$ ecosystems between urban space and natural space $\bullet$ recycling resources? - metamorphosis with nature - five elements in harmony: wood, fire, earth, metal, water $\bullet$ recommendations for reusing resources $\bullet \bullet$ mobility and environment $\bullet$ selforganized system? $\bullet$ space and resource optimization • human beings, consumer goods 
and cultural landscape residues $\bullet$ recommendations for cross-linked flows $\bullet \bullet$ security and gender main-streaming - freedom without control? - society, city, technology and resources - university between globalization and educational landscape • recommendations for social sustainability $\cdots$ art and economy $\bullet$ social art on the campus? - theses for promoting self-organization - alternative economies, alternative societies $\bullet$ recommendations for cultural sustainability •

\section{Learning from the new reality}

- The self-understanding: Making places that seek a dialogue with creation, hoping we encourage the people who experience our spaces to unconsciously perceive them.

- The outside view : Thomas Madreiter, Director of the Department for Urban Planning, Municipality of the City of Vienna, Austria

Laura P. Spinadel and her team from BUSarchitektur set one of the most important examples for urban planning in Vienna during the past decades. Based on the Masterplan from Laura P. Spinadel the campus of the Vienna University of Economics and Business (WU) stands out due to its extraordinary urban and architectural quality. It can be seen as a new landmark, a lighthouse-project for Vienna. Reacting to such highly diverse demands of users in a holistic way by using creativity as well as highly analytic conceptual thinking has seldom been succeeded in such an outstanding way. Laura P. Spinadel managed to develop a new district within one of the most heterogeneous urban areas of Vienna - located at the transition between the densely populated Gründerzeit buildings, the Vienna Fair Area and the green space of the Vienna Prater - that has been accepted by the students and teachers as well as by the Viennese population with great pleasure. The Campus WU radiates far into the adjacent districts with its vitality. The new University of Economics and Business based on Laura P. Spinadel's Masterplan must be seen as THE essential impulse to upgrade an urban area close to the Danube river that laid in a deep sleep until then. With the Campus WU, new scales in architectural and urban planning have undoubtedly been set in Vienna but also internationally. 
Figure 15. Multiple Networking: More than a mere building, the Teaching Center at the new Campus of the Vienna University of Economics and Business from BUSarchitektur is a learning platform that promotes spontaneous communication while also making it possible to undertake the classes and activities that occur within. This quest for spontaneous exchange has different levels and scales sharing one common denominator: the path is the goal.

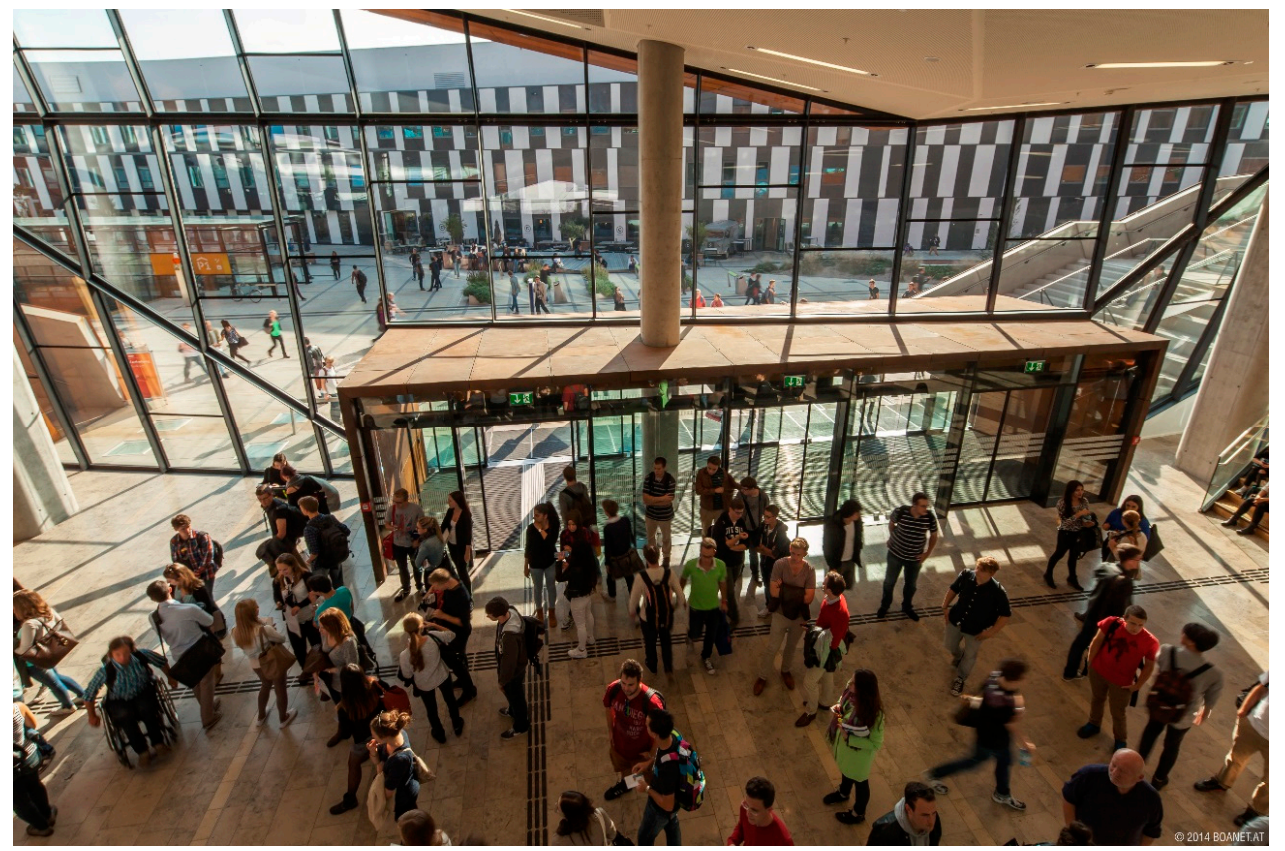

Figure 16. Education Strolling: The Forum Plaza from BUSarchitektur located in front of the Teaching Center's main entrance is as much an exterior world of the Campus, as an extended interior world. Spatial versatility is experienced across "The Space In-Between for Communication" of the Teaching Center's dense body, as well as via the interior staircases and ramps inside and outside the Aula.

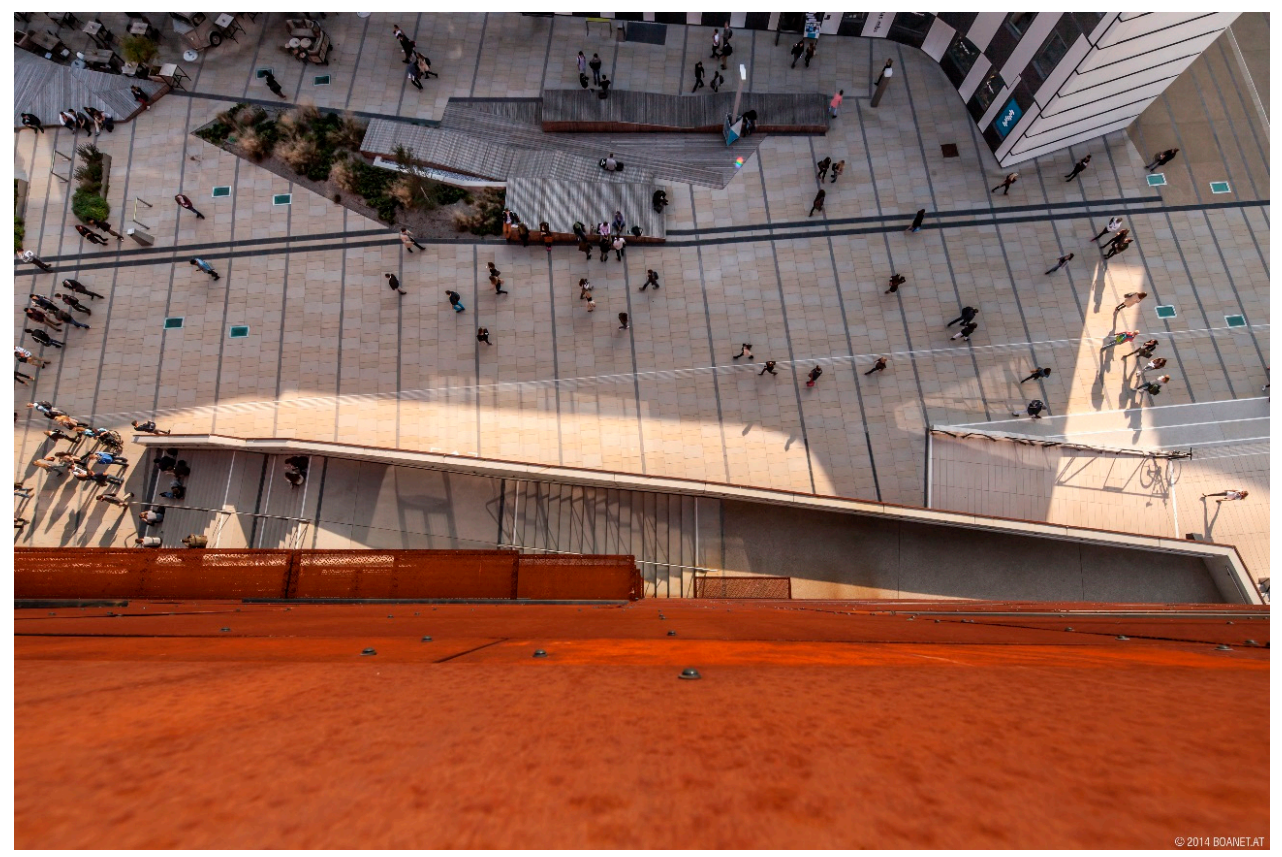


Figure 17. Distending Exchange: The Forum Plaza features broad wooden chaise longue style benches that allow people to relax, communicate and expand their minds after classes in the Teaching Center or after sporting activities in the Student Center from Hitoshi Abe. It is situated at the eastern access point and is largely frequented by students on their way to or from classes. It features terraced wooden land-art, emphasizing this entrance to Campus WU. The space comprises compact raised island platforms bordered by long benches as well as groups of trees and shrubs.

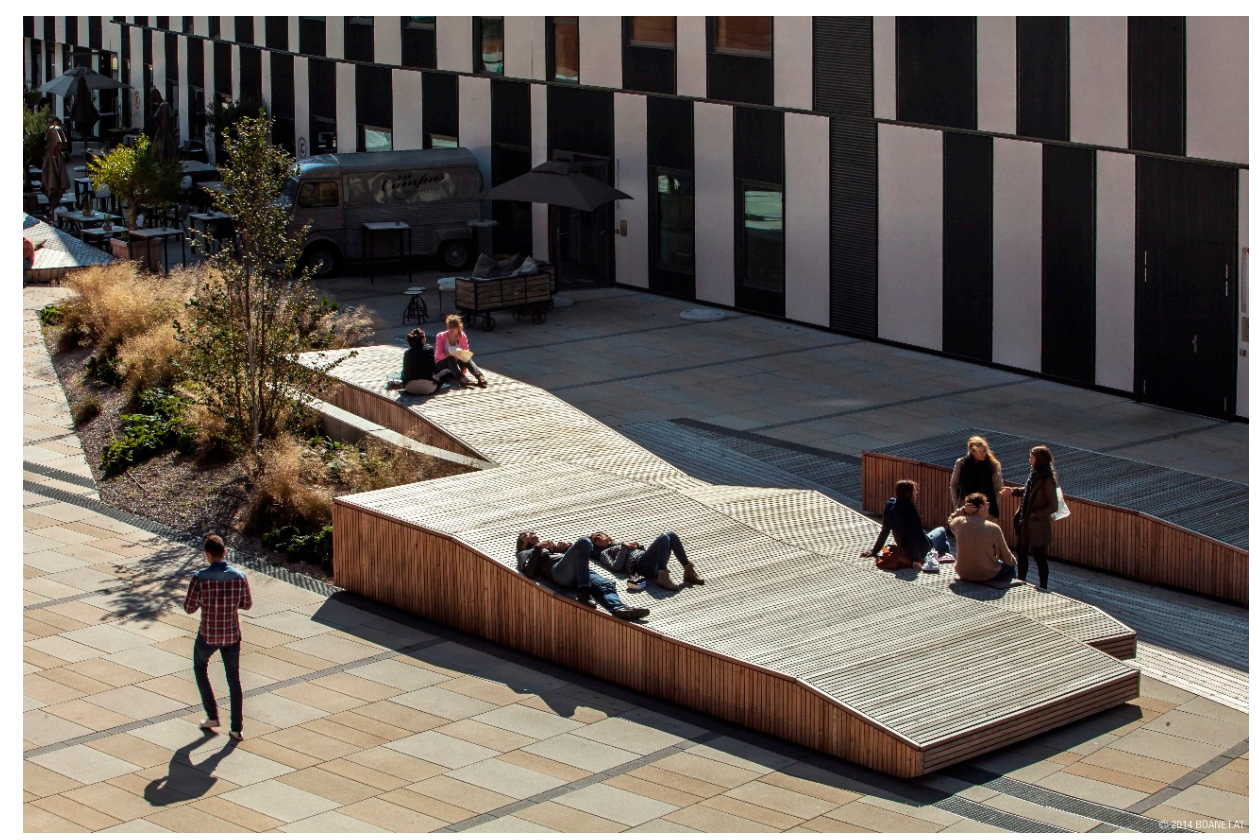

Figure 18. Interact: The Lounge Plaza from BUSarchitektur in front of the Executive Academy from No.mad is a space for play and leisure on the one hand and the framework for more representative activities at the University Graduate Studies building on the other. Its language seeks to create a strong impression on casual visitors to Campus WU.

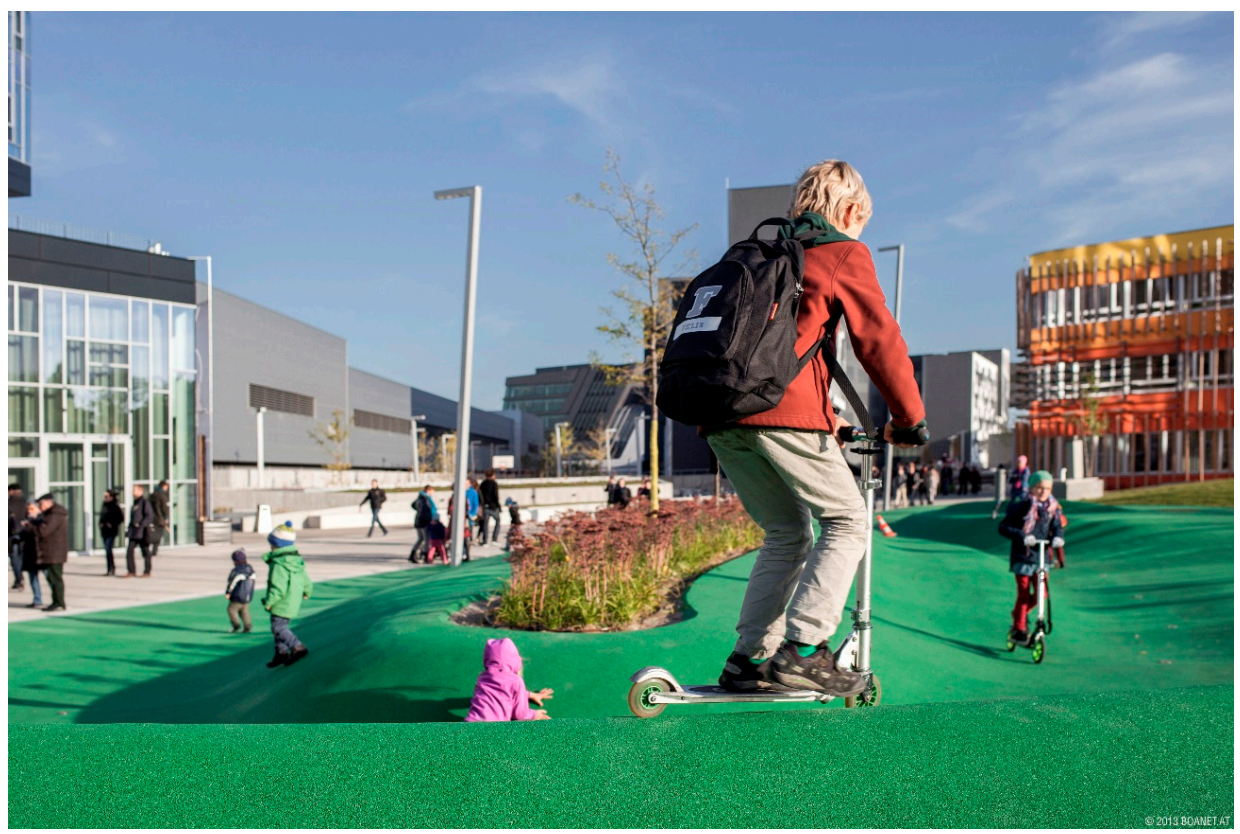


Figure 19. Incidental encounters: The Lounge Plaza constitutes the Campus 'reception' area in front of the Executive Academy. It is characterized by waiting areas and places for incidental encounters. A modelled landscape is partially covered by trees in an umbrella-like fashion. Flexible, colored synthetic elements invite people to sit and lie down. The edge facing the Prater rises continuously, forming a transition towards the undulating terrain of this public space.

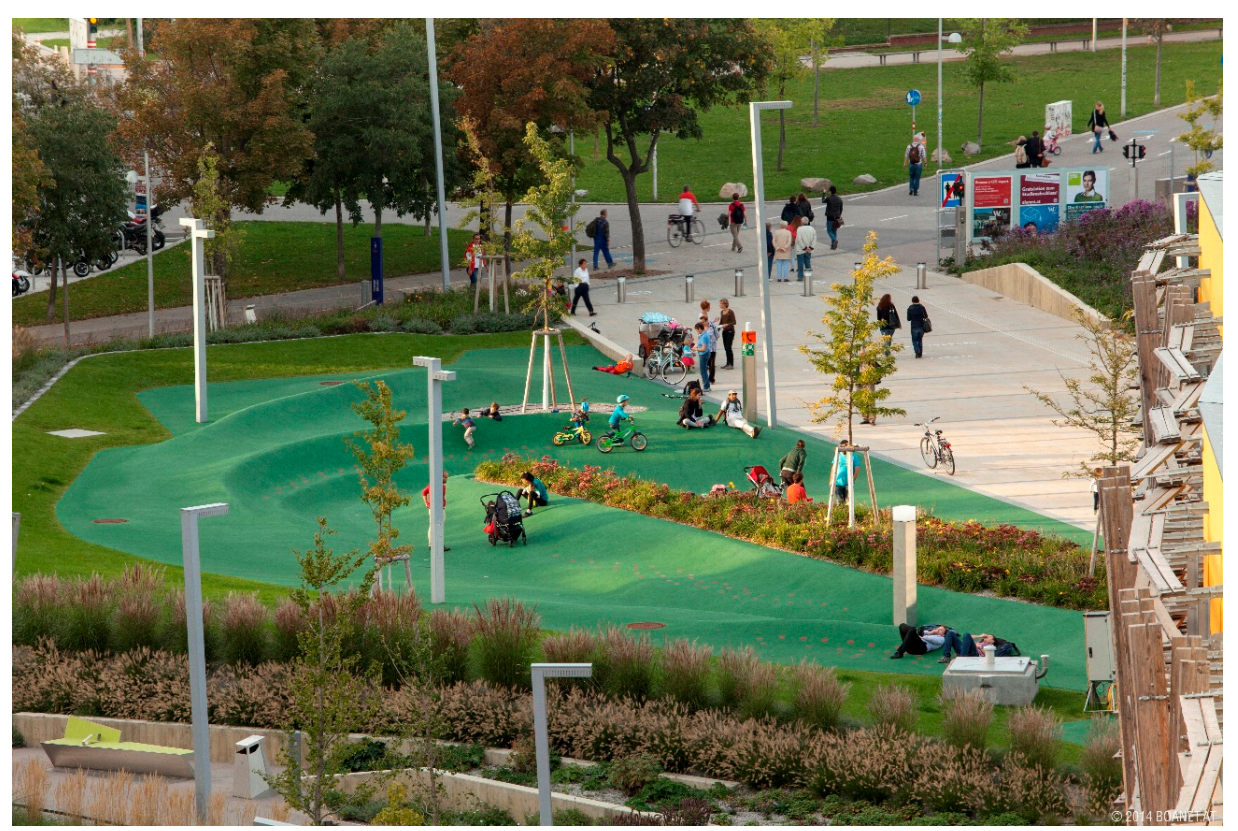

Figure 20. Osmotic: The entire Campus is surrounded by trees and shrubs that function as a natural green boundary. It represents a filter towards the adjacent Prater Park and the city, as well as for the local vehicular traffic. The Campus is accessible through 6 entrances and 5 pedestrian passages 24 hs a day. Campus WU's green boundary comprises various spatial situations and is established in different layers, which are perceived in all their dimensions.

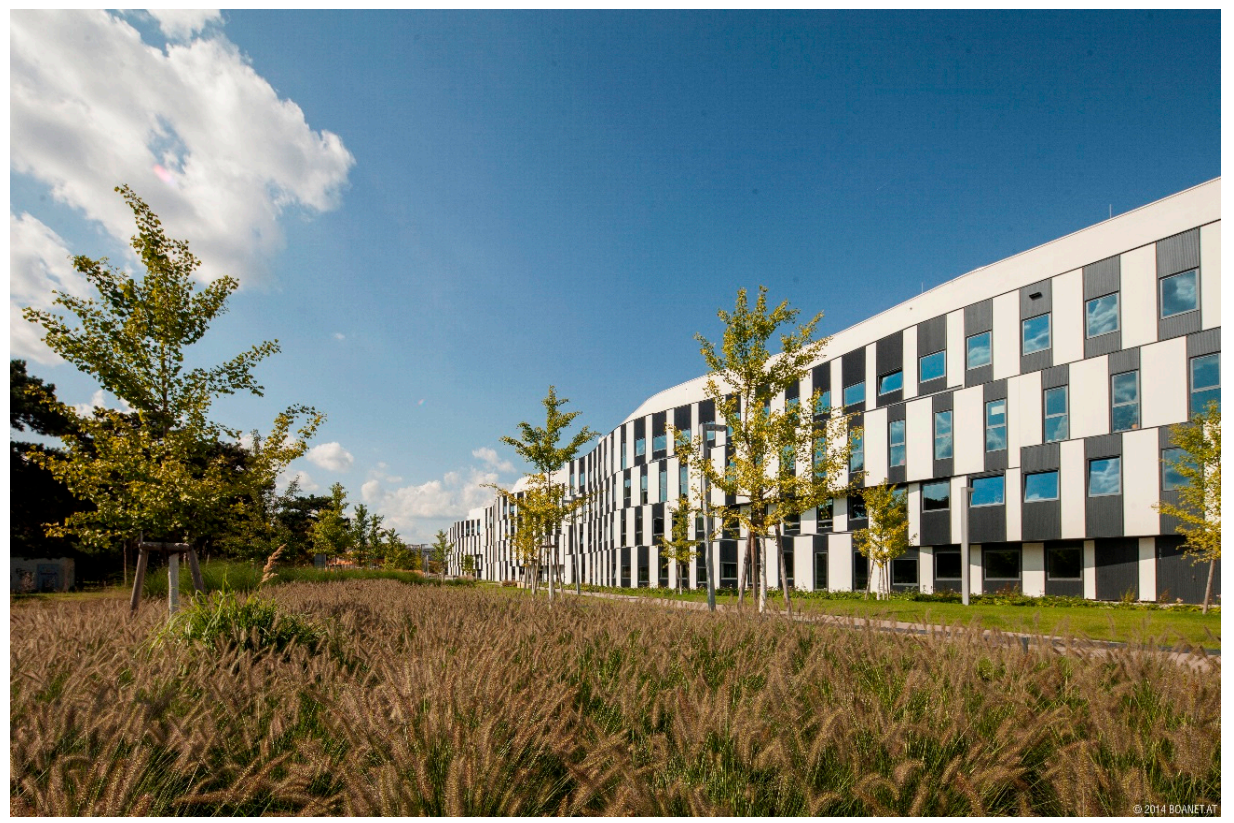


Figure 21. Ecosystem: Ornamental grass clusters assume the role of 'vegetation guides' throughout the network of open spaces. Towards the end of the year, when the summer bloom is over and winter is on its way, they come into their own and serve to form ever stronger structure. Wide perennial spaces follow the concept of "families", whose color and texture effects are related to family colors. When selecting blooming plants their aptitude to serve as food for honeybees was considered. Who knows, we might be able to taste special Campus produced honey soon.

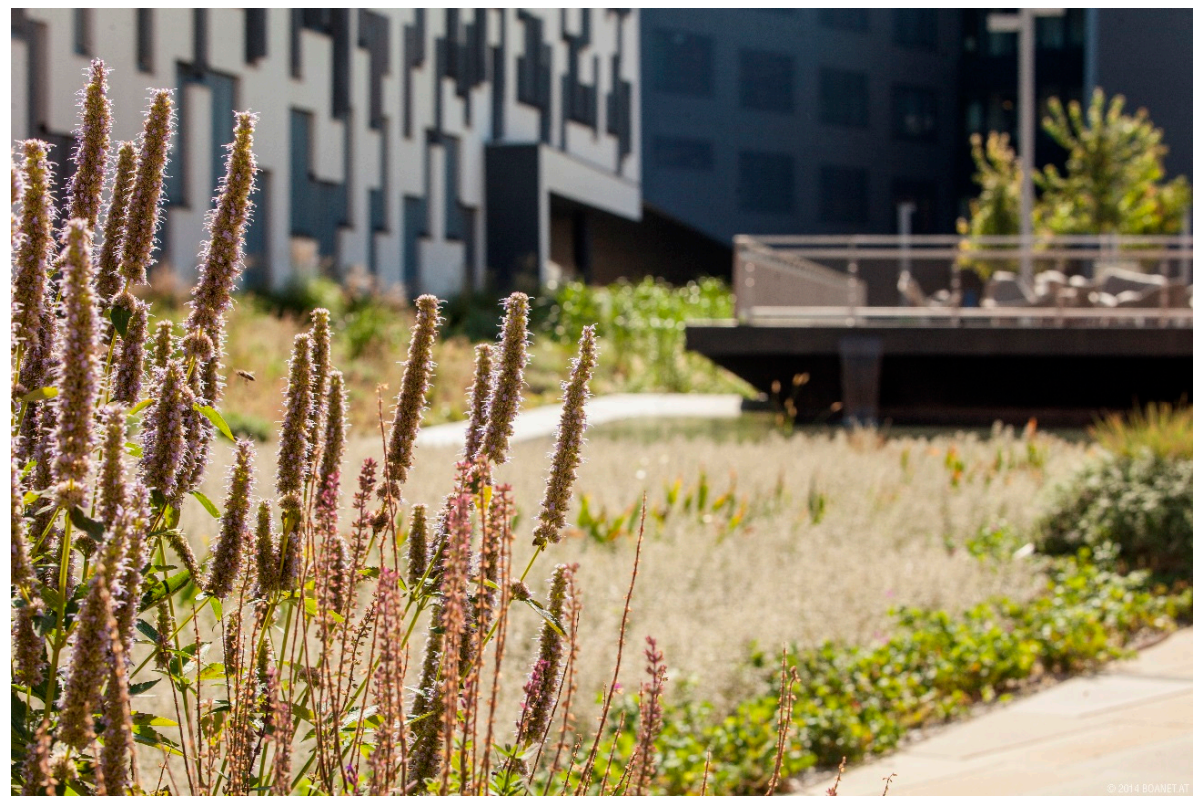

Figure 22. Reinterpret: An island-like structure in the open space, elevating itself above a water area, which modifies its width. The island can be reached by ramps and stairs. It can also be used as an outdoor space by the adjacent café. One solitary tree provides shade and constitutes a landmark. Everyone is invited to rest and chat on the edge of the water pond, where one shall find some plants, being slightly elevated in relation to the other open areas.

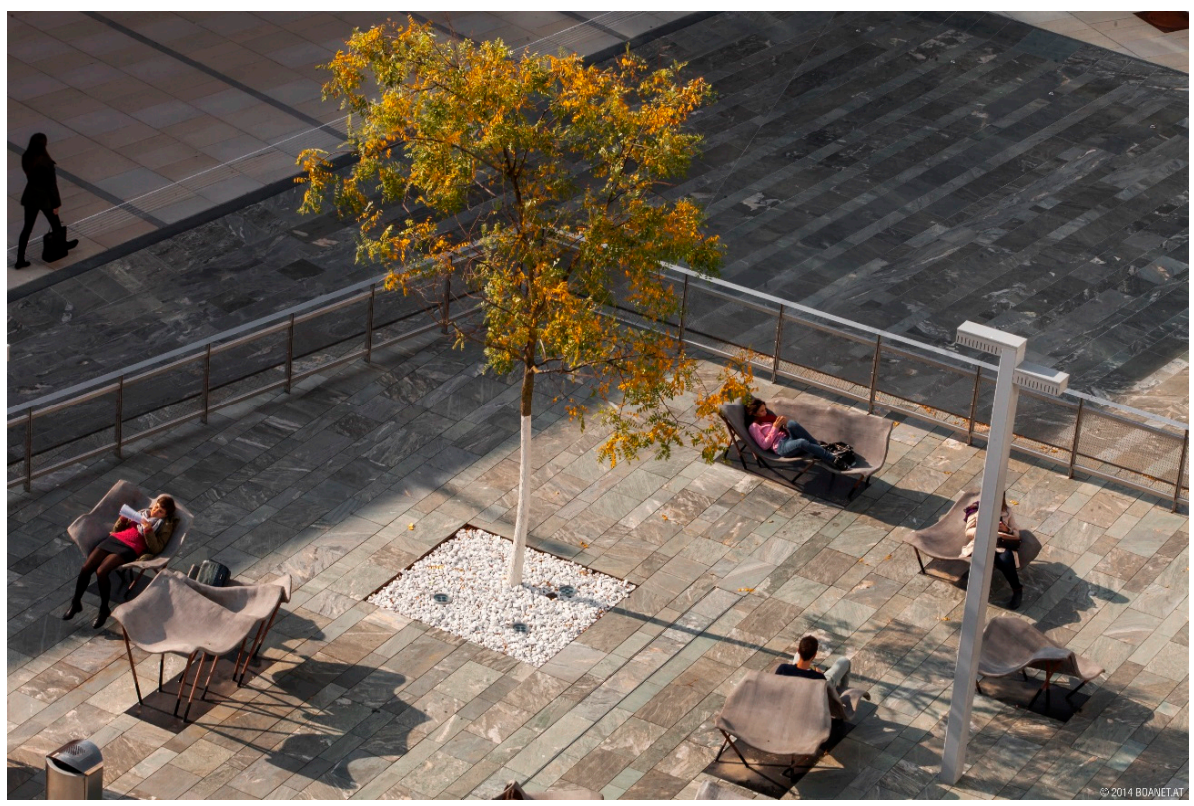


Figure 23. Contemplate: The Relax Plaza is Campus WU's "coastal" area with lots of sunlight and an elevated platform overlooking a reflecting pool of water in front of the Departments building from Carme Pinós. This urban balcony is suitable both for group meetings and for individuals to stroll under the trees in the plaza.

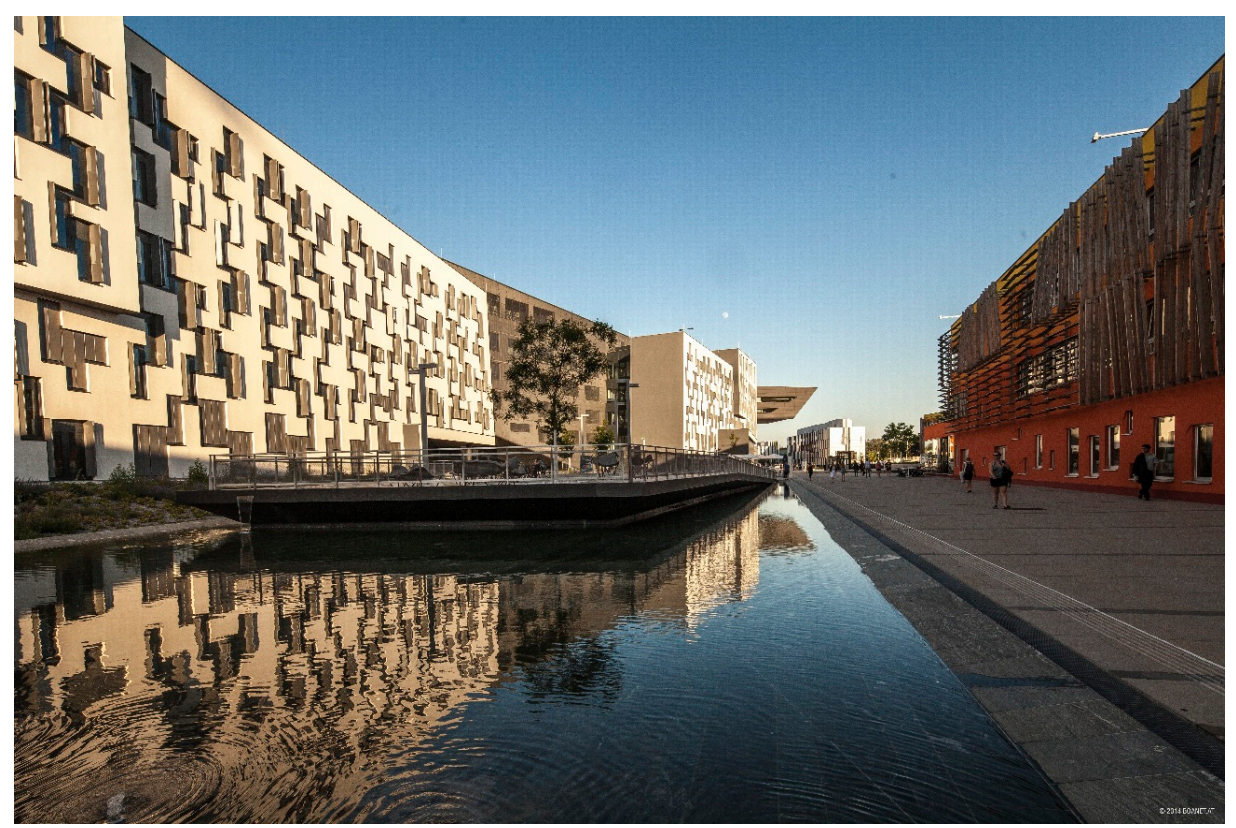

Figure 24. Flying shape: Stage Plaza is a landscape created to provide space for sitting or lying down on its south-facing platforms; it is ideal for seeing and being seen, whether watching how others use the space around you or how it comes alive in one of the events this multifunctional plaza can hold, with the addition of technological support. Here people are both actors and observers. Constructed from precast concrete set with green-tinged gravel, Stage Plaza's raised platform provides panoramic views as well as a space underneath for storing bicycles.

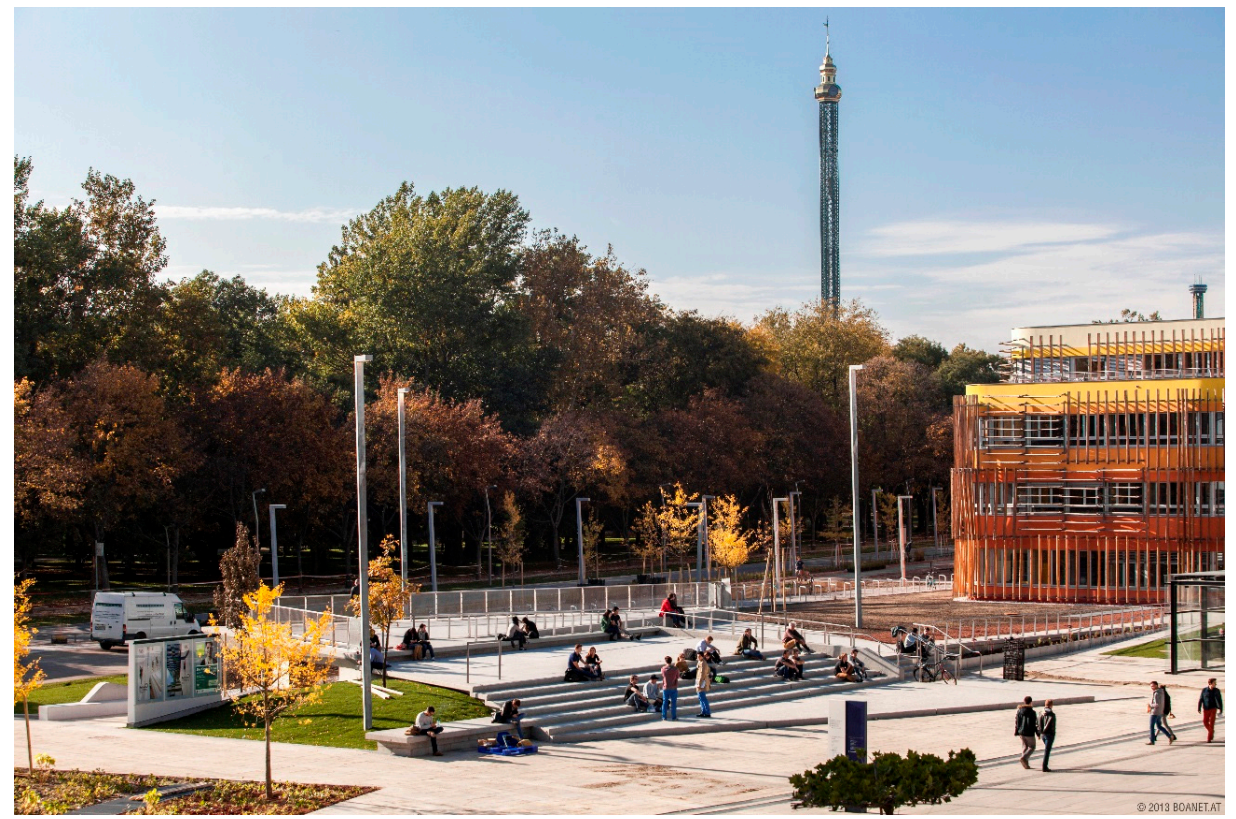


Figure 25. Happening: The Stage Plaza from BUSarchitektur is a place for contemplating the central building of the Library \& Learning Center from Zaha Hadid. It is the largest open space on the Campus with nearly $4,000 \mathrm{~m} 2$ defined by a border of grandstand steps that provide seating for mass events.

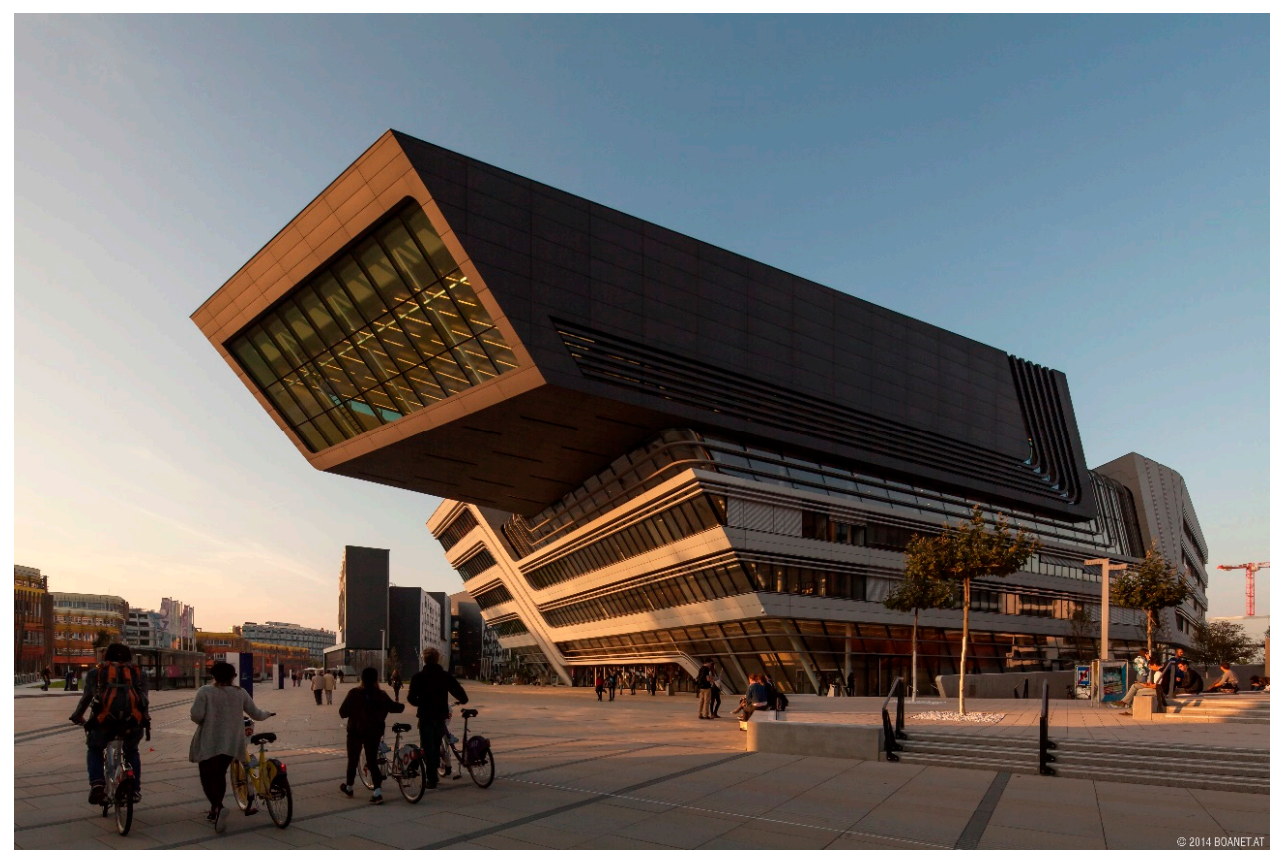

Figure 26. Socialize: The Patio Plaza from BUSarchitektur is integrated into the Teaching Center and through its many levels it connects the study areas on the upper level of the basement with the platforms and stairways leading to the Food Court, as well as with the cross-campus pedestrian walkway.

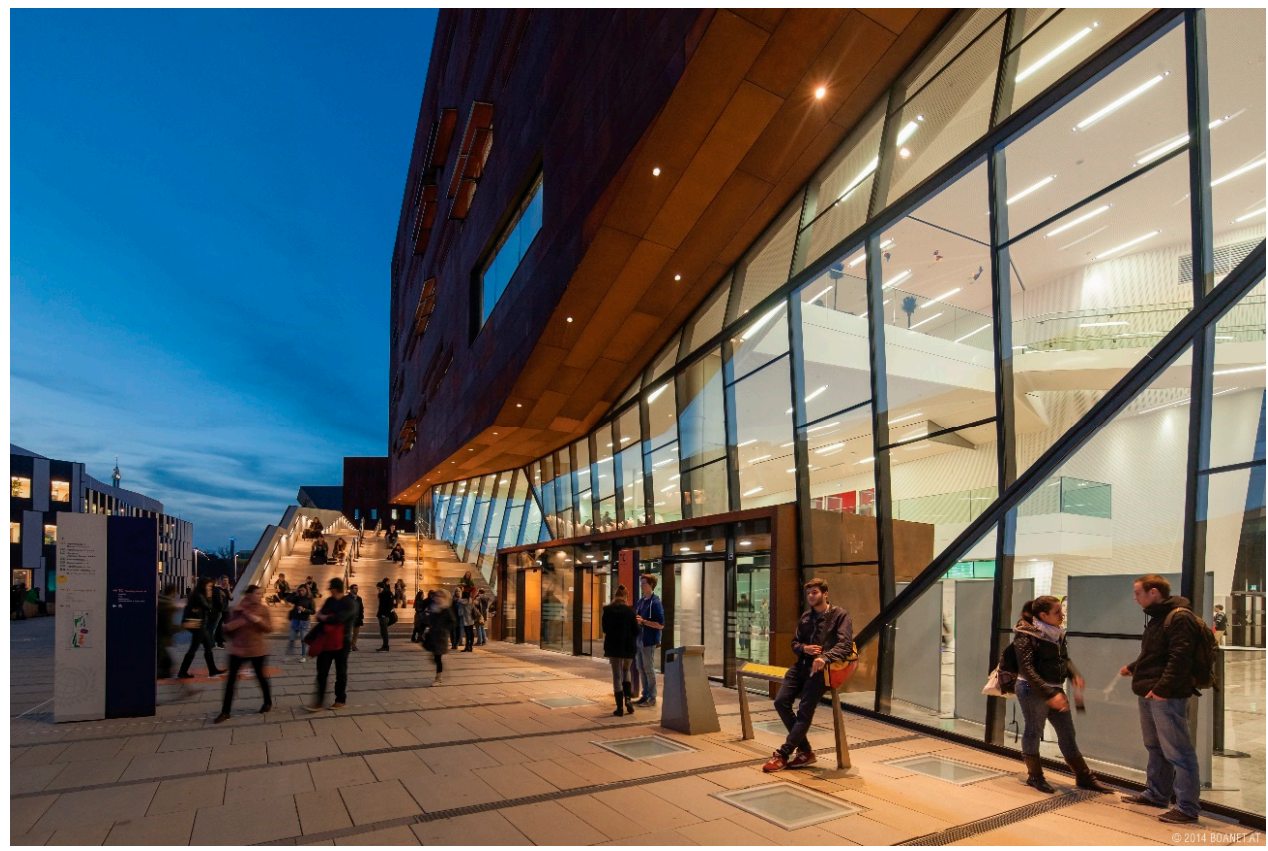


Figure 27. Urbanity: Through a simple language and complex spatial sequences, the Teaching Center at Vienna's new Campus WU makes it possible to recognize the signs that encourage society to form by means of architecture. Here, places for leisure and recreation appear together with plazas that allow interactions between movements, events and spaces; or, in other words, connections between people, activities and architecture are conceived.

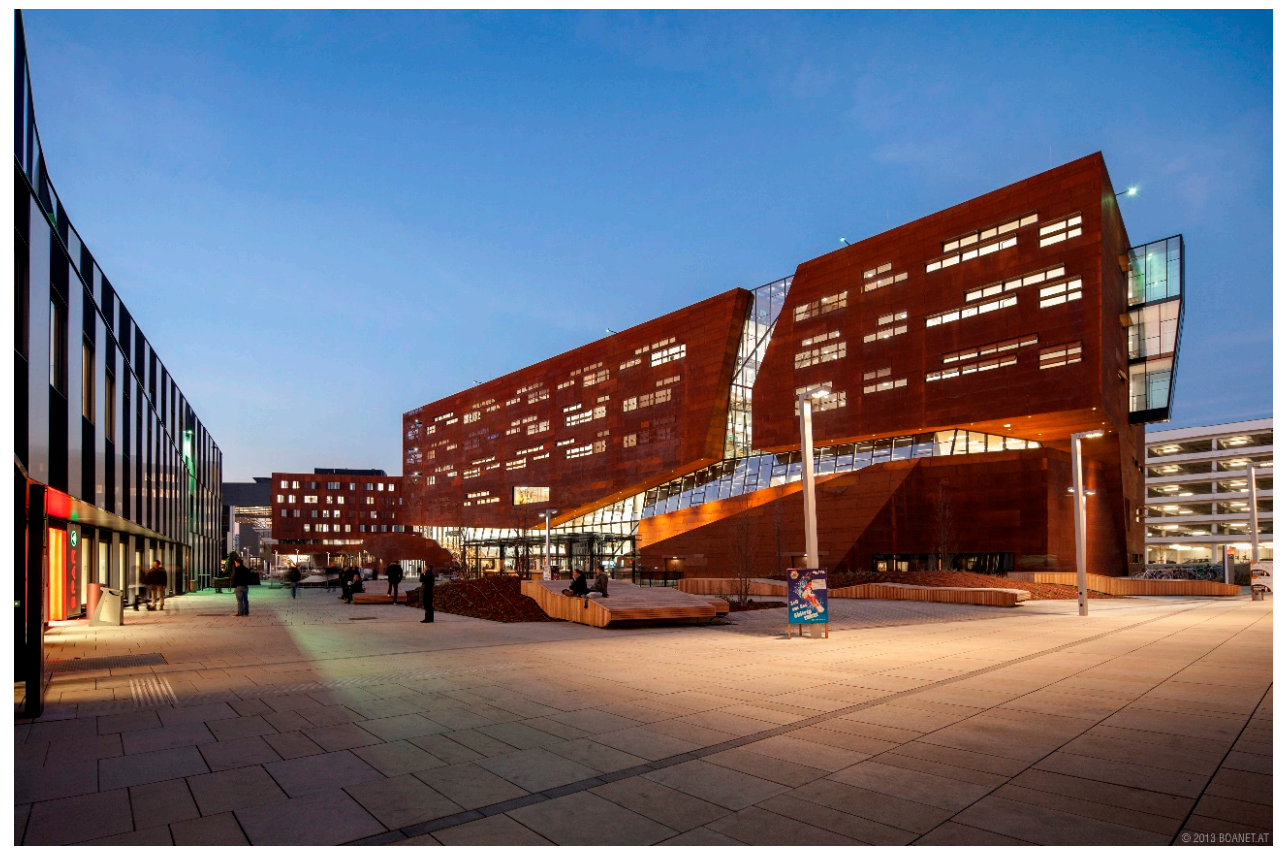

\section{Holismus as multi-tasking}

Ultimately, striking the balance between personal achievement, objectively technology, cultural interaction and social urges, means recognizing the importance of permanently changing our point of view and encourages us to take other factors into consideration. Every single detail should force us to recognize the many different ways a given intervention's micro-action can be interpreted and to proceed accordingly. However, our open-minded approach to searching for added-value, which must necessarily incorporate our actions, often leads us to adopt casual strategies for managing projects. The imbalance between the four quadrants is the starting state that compels us to set off interrelated chain reactions in an attempt to awaken the potential for coOpetition (3). This potential is present both in the direct actors and in the domino effect that will occur once we take control of the reality in which we act. CoOpeting public and private actors that acknowledge the simultaneous presence of both cooperation and competition when talking about quality of life and capital repayment. Competing cooperatively in order to successfully invent and develop alternative design mechanisms to those of globalization.

Intellectual curiosity as a journey to discover not-so-obvious game theory applications in architecture - this is our way to play an active role in our daily productive output. The game played is a game of society since it leads to the socialization of the individual in a virtual community and, as a consequence, to the development of a real community. The only way for Campus to have a future is if we activate the urban potential of the educational habitat. 
Figure 28. Real experiences: Strategic actionism can be worth a thousand words in order to initiate processes for participating and taking ownership of the new Campus WU in Vienna. To develop communication tools that enable the academic community to comprehend architecture's cryptic language and evaluate the spatial qualities of inhabiting. By managing to communicate that the "object of desire" can have as much added value for the immediate area, as for the city and the country as a whole, thereby enabling complementary work.

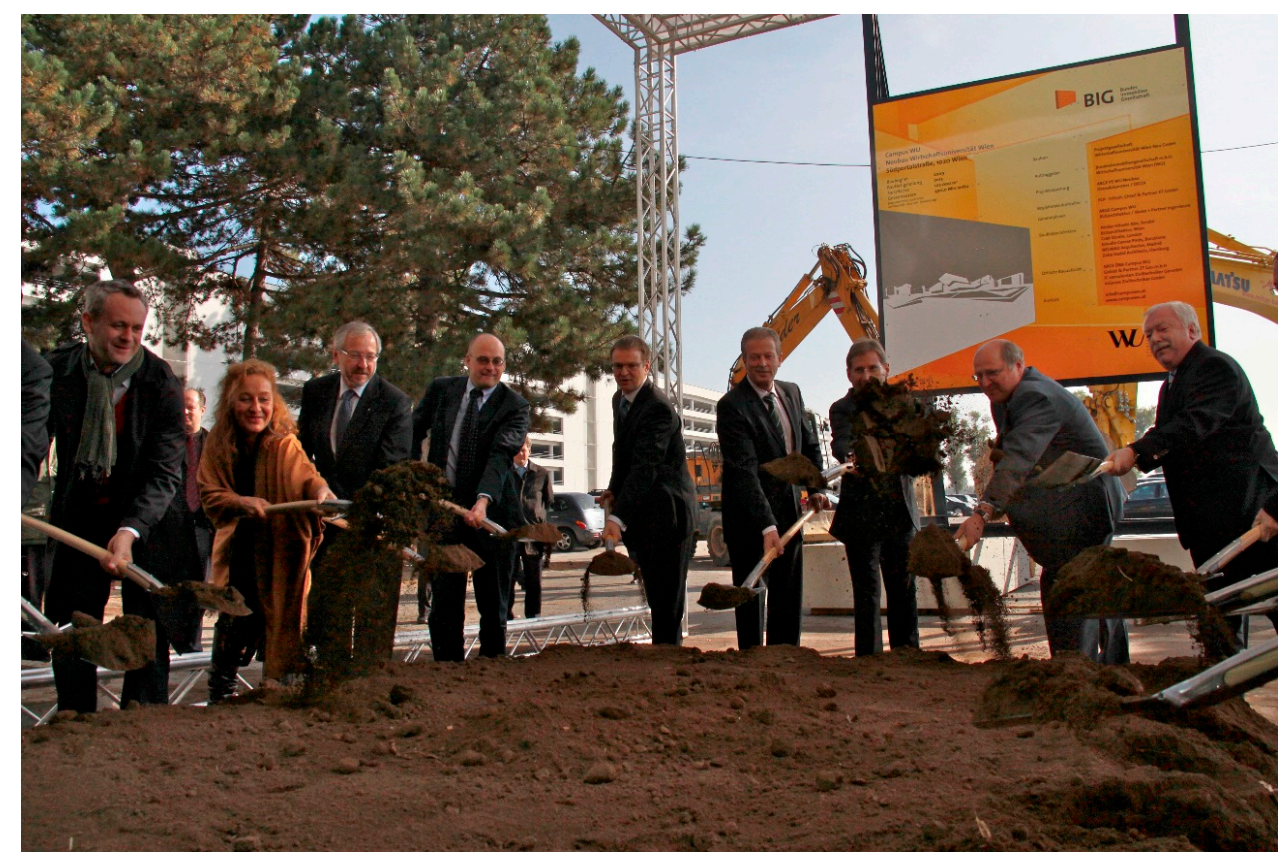

\section{Acknowledgments}

BUSarchitektur, www.busarchitektur.com; BOA office for advance randomness, www.boanet.at; Vienna University of Economics and Business; Projektgesellschaft Campus WU GmbH.

\section{Conflict of Interest}

The authors declare no conflict of interest.

\section{References and Notes}

1. Peter Suber, The Paradox of Self-Amendment: A Study of Logic, Law, Omnipotence, and Change, USA; 1990; ISBN-10: 0820412120 ISBN-13: 978-0820412122.

2. Ken Wilber A Theory of Everything. An Integral Vision for Business, Politics, Science and Spirituality, USA 2000; ISBN 3-924195-79-X.

3. Adam Brandenburger, Barry Nalebuff; Co-Opetition : A Revolution Mindset That Combines Competition and Cooperation, USA, 1996; ISBN 0-385-47950-6. 
4. Ila Berman, Mona El Khafif, Multi-Scalar Negotiations:Master Plan as Mediator. In Campus WU A holistic history, $1^{\text {st }}$ ed.; Publisher: BUSarchitektur, BOA büro für offensive aleatorik, Austria, 2013, pp.60 ISBN-10: 3950366601.

(C) 2015 by the authors; licensee MDPI and IFoU, This article is an open access article distributed under the terms and conditions of the Creative Commons Attribution license. 